The Journal of Quality in Education (JoQiE) Vol.11, N¹8, November 2021

\title{
Cannabis cultivation as a factor influencing scholastic performance:
}

\section{The case study of Ghomara's secondary school students (Chefchaouen}

\section{province, north-western Morocco)}

\author{
Yassin Meklach $^{1 *}$ and Abderrahmane Merzouki ${ }^{1}$
}

* Corresponding author.

E-mail address: yassin.mclach@gmail.com

${ }^{1}$ Department of Biology, Faculty of Sciences, University Abdelmalek Essaâdi, Morocco.

\begin{abstract}
:
The secondary school performance of Ghomara's students (coastal area of Chefchaouen province, Rif Mountain, Morocco) is deeply influenced by the cultivation of cannabis practiced by many Ghomarian families. To highlight this relationship, a field study was conducted with students, their parents, and other stakeholders through the adoption of a quantitative and qualitative sociological approach. It then appears that most of the students, especially boys, from cannabis families had annual averages assessment marks (AAM) less than 10/20. These marks do not allow them to continue their schooling. In addition, other factors are added to aggravate the already precarious situation, such as the need for manpower to carry out family farming activities, the social reluctance towards education, the inadequacy of education system to the labour market and the mistrust of the local population to the reforms of the national education system recently proposed by the government.
\end{abstract}

Key words: School performance, education, cannabis farmers, Ghomara, Rif, Morocco. 
The Journal of Quality in Education (JoQiE) Vol.11, N¹8, November 2021

\section{Introduction:}

The universal goal of the education system is generally to improve human development and strengthen understanding, tolerance and friendship among nations including racial or religious groups according the 26th article of the Universal Declaration of Human Rights (UDHR 1948).

In Morocco, with the progress made to develop educational system, it is noted that this later is facing increasing and complex challenges including schooling-drop and access to good quality education for children and young people. Despite the consecutive implemented reforms, the education system in Morocco is still suffering from several handicaps, such as dropping out of school which threatens thousands of students every year and forces them to leave school before obtaining a diploma (CSEFRS 2019).

Since 1999, the educational system of Morocco claims, through the national charter of education and training, to generalize schooling and improve the quality of education mainly in rural areas. Ten years later, the new proposed reform of education called "the emergency program" has been established to further strengthen schooling to the age of 15 , empowering and motivating students in secondary schools and universities, and above all overcome the previous cross-cutting issues of the educational system. Unfortunately, huge gap remains to achieve the foreseen goals, and Morocco remains among the last ranked countries in regard to the quality of education (120 of 137 countries in 2017 (GCR 2017-18)). Regarding the fundamental learning skills; a new indicator called "learning poverty" 1 just ranks the country outside the international standards with a value of $68.6 \%$ and is 2.5 points worse than the average in the Middle East and North Africa (MENA) (World Bank 2019). In addition to that, the programme of international student assessment (PISA), that evaluate 15-year-old student's

\footnotetext{
${ }^{1}$ The Learning Poverty indicator combines the concepts of schooling and learning at the end of primary education, building on indicators of reading proficiency and school enrolment.
} 
The Journal of Quality in Education (JoQiE) Vol.11, N¹8, November 2021

abilities in reading, mathematics and science, placed Morocco 75 out of 79 participated countries (OECD 2019). Therefore, the problem of education in Morocco clearly reflects the current situation of country development. The adult illiteracy is still embarrassing with a value of $32.2 \%$ in total and $43 \%$ among women (HCP 2018).

Furthermore, the rural society is severely vulnerable. In addition to low access to basic services (electricity, water, health care and transport), it is suffered from high unemployment rate forcing young people to drop out of school very early to look for work. The income from the cannabis cultivation is so attractive that young students drop out easily from school to start their own cannabis business or support their family business in growing cannabis.

According to authors knowledge, there are few studies that directly address the culture of certain drugs, child labour and school performance like a study which treats the cultivation of coca ( Dammert 2007) and the other that of Khat (Ngeranwa 2013) and no previous research intended to shed light on the relationship between performance scholastic of student and growing cannabis in MENA region. Nevertheless, this relationship was studied in regards to consumption and drugs addiction (Shapiro et al., 2010; Anglin et al. 2012; Bidwell et al. 2014; Pacoricona Alfaro et al. 2017; Walukevich et al. 2019; Schultz 2019; Mason et al. 2019).

Hence, and to be more precise, there was no studies examining the impact of cannabis cultivation, as a "rural" farming activity, on the school performance of farmer's children.

In the studied region, most students of the secondary school come from families that grow cannabis. Thus, and within the context of the social phenomena associated with the cultivation of cannabis in Ghomara, through ethno-sociological surveys (Meklach et al. 2010; 2017), it was noticed that there is a remarkable difference between annual assessment marks of students belong to farmers that grow cannabis and their classmates.

To highlight the possible relationship that may exist between student performance at school and the cultivation of cannabis as an extended family practice in the study area, a field 
The Journal of Quality in Education (JoQiE) Vol.11, N¹8, November 2021

research was carried out using a questionnaire supplemented by interviews with the local population.

\section{Material and methods:}

\subsection{Setting:}

This study was in collaboration with the provincial educational institution in Chefchaouen and the faculty of science of Tetouan. It took place through four rural municipalities namely; Stehat; Bni Bouzera; Bni Mansour, and Bni Selman, all affiliated to the tribal of Ghomara (Figure 1). The geographical extension of these rural municipalities bordered on the northeast side by the Mediterranean Sea, on the northwest side by the river of Oued Laou, on the southwest by the rest of the rural communities of Chefchaouen, and on the southeast by Al Hoceima province. The study focuses on the downtown of Stehat municipality, which accommodates students coming from the four above mentioned municipalities, and thus may reflect the main characteristics which mark the problem of schooling in the study area.

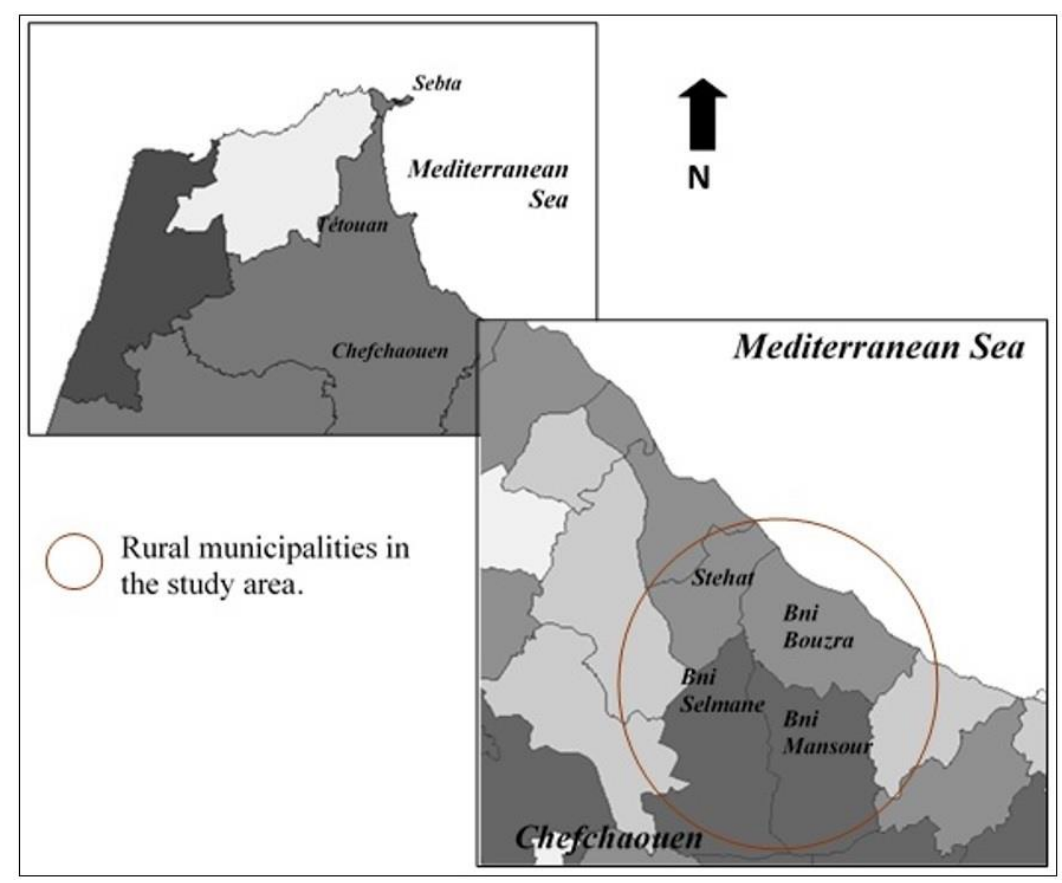

Fig. 1 : Geographical location of the study area

\subsection{Participants:}


The Journal of Quality in Education (JoQiE) Vol.11, N 18 , November 2021

In the secondary school concerned by this study, we held three meetings with teachers in order to present an overview of the study and how to accomplish it. A total of 5 teachers out of 22 who attended each of these three meetings expressed their willingness to participate and to pass the questionnaire to their students in order to collect the quantitative data. We also contacted all other interested people in the village to actively attend future focus groups for qualitative data and provided their names and contact information for future meeting.

\subsection{Procedure:}

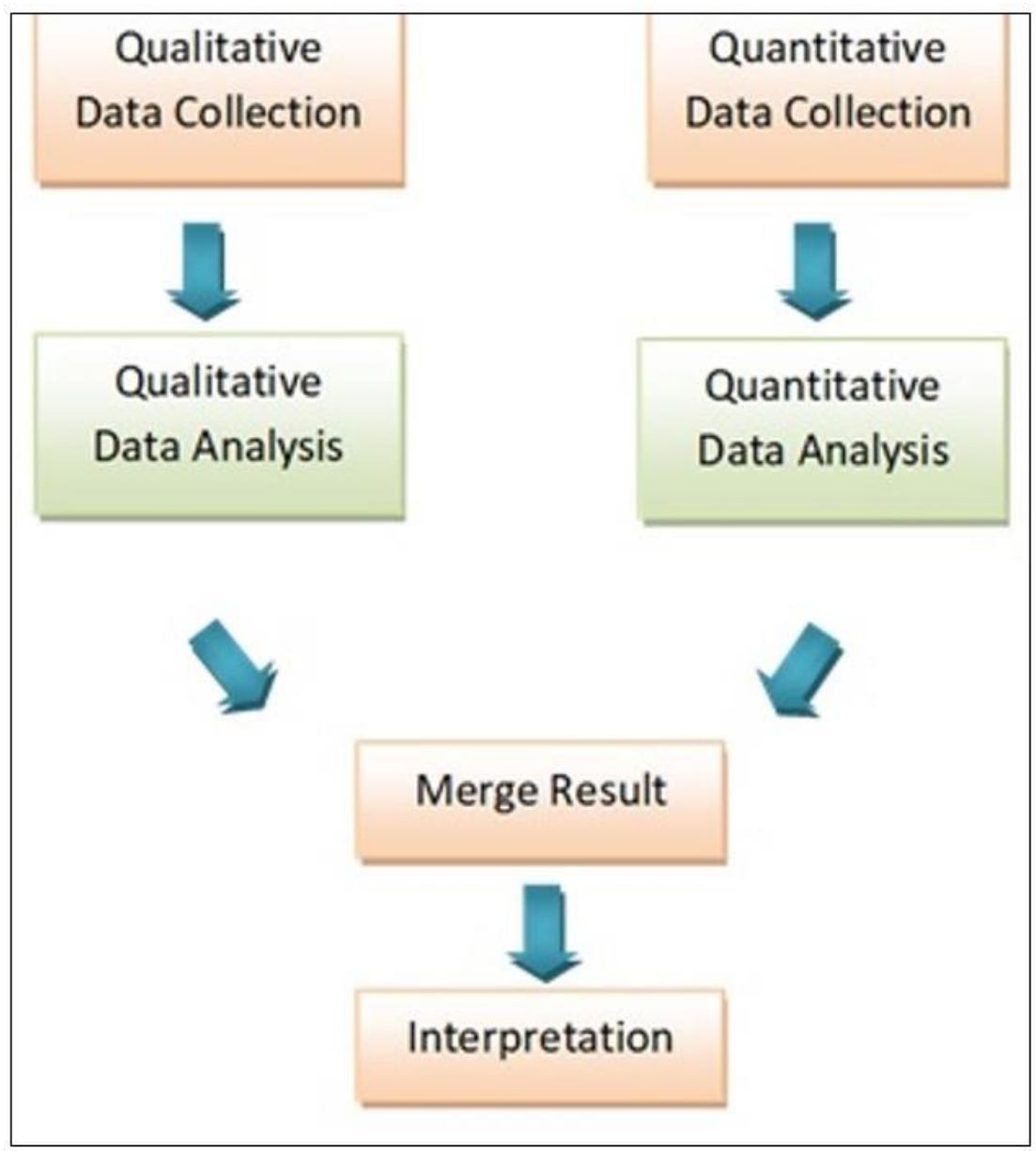

Fig. 2 : Convergent mixed methods design. Adapted from Creswell \& Plano Clark (2011).

Adoption of a mixed-methods approach, inspired by sociological and anthropological methods was crucial to explore the phenomenon. In addition to supplementing statistical information, it made it possible to better explain the mechanisms that control the studied 
phenomenon. Qualitative methods can be also used to implement quantitative methods or to extend results of survey data by exploring them in further depth. The qualitative interviews undertaken in this study represent personal narrative experiences based on interpretive sociology perspectives (Coffey \& Atkinson 1996; Silverman 1999), in particular, the perspectives of active interviewing (Holstein and Gubrium 1997).

From the design perspective, a convergent mixed method was used where quantitative and qualitative data were collected in same time, analysed consecutively, and then merged in overall analysis and interpretation (Creswell and Plano Clark 2011) (Figure 2).

In this work, a qualitative analysis can highlight the cause and effect relationship between the parents' representation concerning the education of their children and the influence of the prevailing activity of cannabis cultivation on their scholastic performance.

The secondary school in which this study was conducted is located in the rural municipality of Stehat. It is considered as a centre for students coming from areas producing cannabis. The total number of students in this secondary school for the 2018/2019 scholar year was 304 students. The number of surveyed students is 100 in which $45 \%$ are girls. This is a random sample in the $3^{\text {rd }}$ grades of secondary school; the sample size selected was considered enough to give decent estimates of measured factors. In addition, this survey was focused on giving clear explanations of the studied phenomena rather than providing the precise measures on their magnitude.

To collect quantitative data, the students were surveyed at classroom. The objective is to illustrate the socio-economic data of their family, particularly those who grow cannabis as main agricultural activity. Being in the classroom provide students freedom to answer the questionnaire without influence from their parents and relative. In addition, it allows student to clarify unclear questions by asking their teacher. This way, author ensure consistency 
especially for sensitive questions related to cannabis cultivation seen as "a taboo" subject among the inhabitants.

In order to analyse this quantitative data, we adopted a diagnostic analysis by the "genetic" method that searches and explains the initial cause and the generating event ("the causative cause"). The counting was manual to avoid overwriting some quantitative data by computer processing. The results obtained were analysed using the STATISTICA version 6 software. A value of $\mathrm{p}<0.05$ was considered statistically significant.

For the qualitative data, the technique used in this survey consists of an open and in-depth interview conducted with local population, namely parents, students and also young people and others involved in the studied area (Table 1). The participants in this part of the study were between 18 and 79 years old, $76.2 \%$ were male and $23.8 \%$ female. They have different family situations and different occupations. We opted for this choice to enrich the debate on the subject and bring out the maximum of opinions.

Table 1: Characteristic of the qualitative sample.

\begin{tabular}{c|cccc}
\hline $\begin{array}{c}\text { Surveyed } \\
\text { people } \\
(n=21)\end{array}$ & Sex & Age & $\begin{array}{c}\text { Number } \\
\text { of children }\end{array}$ & Profession \\
\hline 1 & Male & 45 & 3 & Farmer \\
2 & Male & 51 & 6 & Farmer \\
3 & Female & 62 & 7 & Farmer \\
4 & Male & 39 & 3 & Farmer \\
5 & Male & 43 & 5 & Farmer \\
6 & Female & 18 & - & Farmer \\
7 & Female & 19 & - & Student \\
8 & Male & 20 & - & Student \\
9 & Male & 21 & - & Student \\
10 & Male & 18 & - & Student \\
11 & Male & 45 & 2 & Employee \\
\hline
\end{tabular}




\begin{tabular}{c|cccc}
\hline 12 & Male & 55 & 6 & Fisherman \\
13 & Male & 23 & 4 & Fisherman \\
14 & Male & 49 & 3 & Teacher \\
15 & Male & 66 & - & Seller \\
16 & Male & 50 & 1 & Seller \\
17 & Female & 37 & 4 & Seller \\
18 & Female & 33 & 2 & No occupation \\
19 & Male & 41 & 5 & Driver \\
20 & Male & 79 & 3 & Chekh \\
21 & Male & 54 & 3 & F'qih ${ }^{3}$ \\
22 & Female & 33 & 1 & Instructor \\
23 & Male & 45 & - & Provincial \\
& & & & administration of \\
& & & education \\
\hline
\end{tabular}

To identify the issues that will be raised with the population, a guide to the interview has been established (Table 2), with some flexibility, so additional follow-up questions could be asked depending on the case (Fylan 2005) including the aspects of the studied issue such as:

- Personal attitudes towards education,

- Availability of human resources and infrastructure related to education,

- Education and employment.

Table 2: Interview guide sample questions.

- In your opinion, what do you think about the education of the child in your village? If you have observed factors negatively influencing children's schooling (Instructors, ways of learning, equipment...)? Can you give specific

\footnotetext{
${ }^{2}$ Local agent of the authorities.
}

${ }^{3}$ Muslim jurist. 
examples? Did you observe a positive impact of the local school on the children, can you give specific examples?

- Knowing the cultivation of cannabis is widespread in the mountains of Ghomara region, does it influence the education of young people? In what ways, if at all?

- How it is the motivation of the young people of the region to continue their education? does cannabis cultivation intervene in this topic?

The analysis of qualitative data began with the textual transcription of audio tapes recorded during the interviews. They were entered on the Atlas'ti 7.0 qualitative data analysis software (Scientific Software Development GmbH, Berlin, Germany). The collected data were analysed by theme and their meanings are summarized by assigning a code to each theme. The codes (or data) were compared and the relations between them were established (explanations, problems, comments ...) by editing the tool "network" on the software. To ensure the objectivity of the work, the codes were analysed by three researchers belonging to the Department of Biology in the Faculty of Sciences, Tetouan, Morocco.

\section{Results:}

\subsection{Quantitative results:}

The results of the survey show that girls represent only $29 \%$ of the total student population compared boys (71\%) (Figure 3). While in the nearest urban school (ex. Ibn-Sina Middle School in Tetouan), girls represent 48.4\% (Delegation of provincial education statistics, 2019) (with a 
total of 874, including 423 girls $^{4}$ ). This low percentage of girls from rural area enrolled in middle school is already registered at national level (CSEFRS 2019). It could be explained by the fact that the future of the girl is predetermined, in most cases, from the start of her life, since her main task is to be a housewife, so her family circle prepares her for future marriage, most often at a very young age. Therefore, his schooling is considered a waste of time and money.

The distribution of students according to the occupational status of their parents (Figure 4), reveals the importance of the category "Farmers" which is about half (44\%). The category "fishermen" represents $23 \%$ while other categories represent $18 \%, 11 \%$, and $4 \%$ respectively for traders, civil servants, and others. This observation is logical, since the study area has a dominant agricultural activity with a strip open to the Mediterranean Sea, suitable for a traditional coastal fishing activity. Usually, according to the daily attendance during the survey, most of those who practice fishing occupation have plots used for agriculture. We can also notice that the percentage of employees remains lower compared to those of free professions, this is consistent with the Moroccan statistical data from the General Population and Housing Census of 2014 (RGPH 2014)

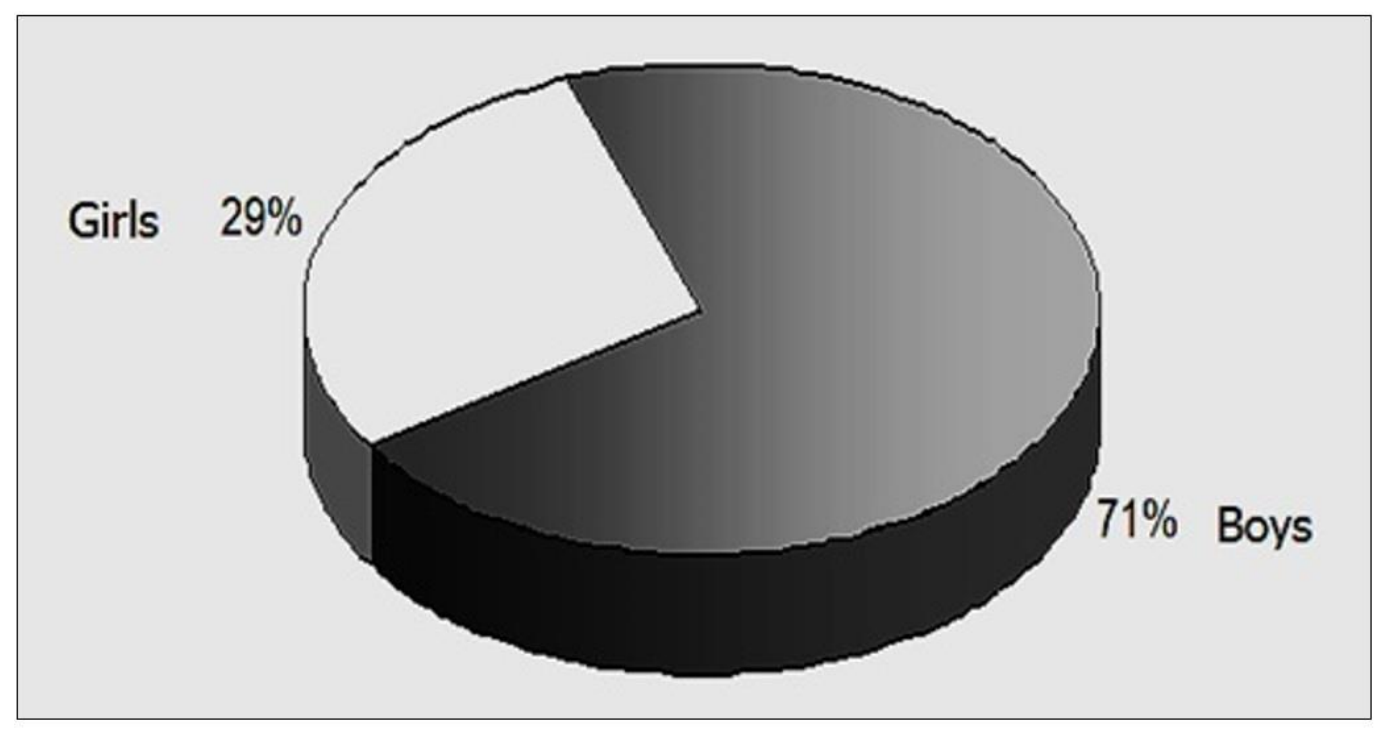

Fig. 3. Distribution of the student by sex gender.

\footnotetext{
${ }^{4}$ http://www.delegtetouan.ma/downloads/2017/Dalil\%202016-2017.pdf
} 


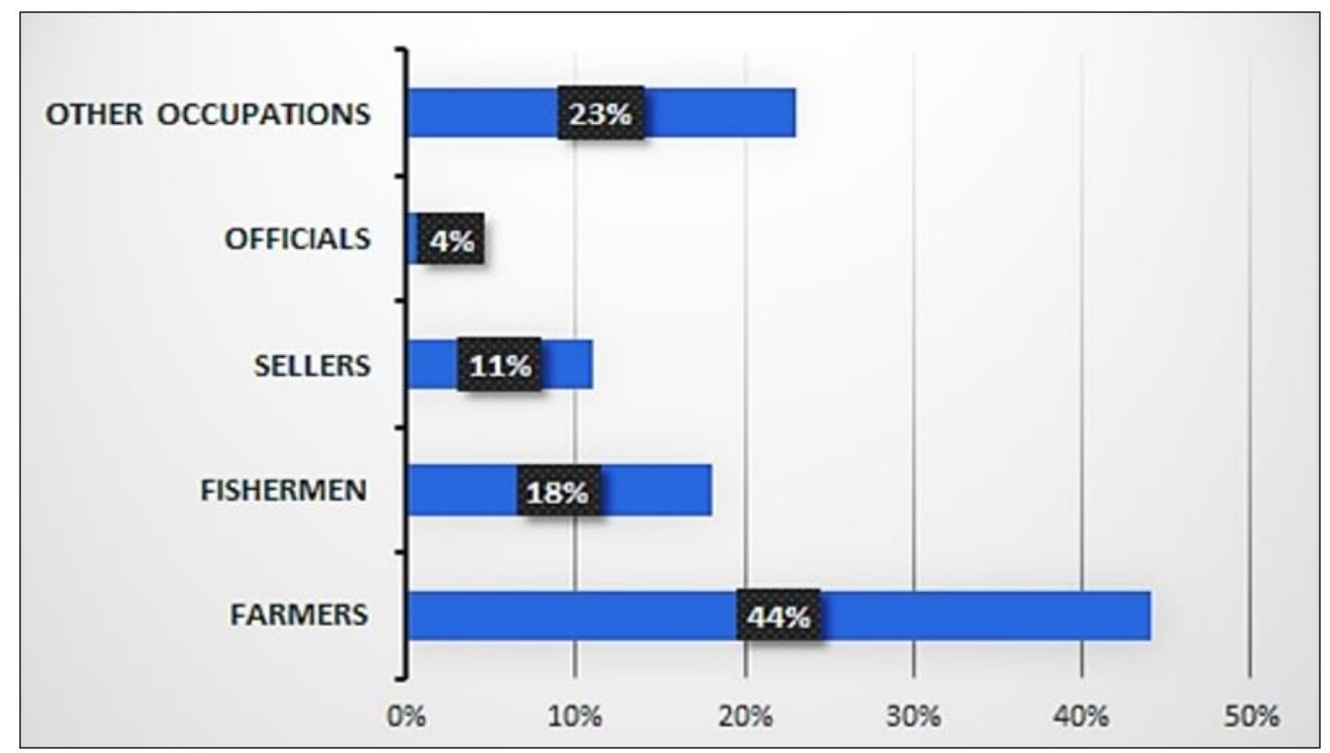

Fig. 4. Distribution of students according to the occupations of their fathers.

As previously indicated, we will quantitatively measure the scholastic performance of the student by comparing their marks. In the same way, we will adopt in this study an annual averages assessment marks of 10/20 since it is, legally, the threshold to pass overall exams and access to higher level in the Moroccan education system. The middle school of Stehat subject of our survey, receives students from 14 primary schools existing in the surrounding rural area.

The distribution of students according to the obtained scores are expressed with the annual averages assessment marks (AAM) (Figure 5). It shows that more than half of the students (52\%) have an AAM higher than 10, and $36 \%$ of them have an average score between 10 and 12. The rest (48\%) have an AAM less than 10. In this last group, $29 \%$ have an AAM between 08 and almost 10, while 19\% have an AAM less than 08 . This result indicates that at the middle school of Stehat almost half of the students find difficulties to progress in the school. 


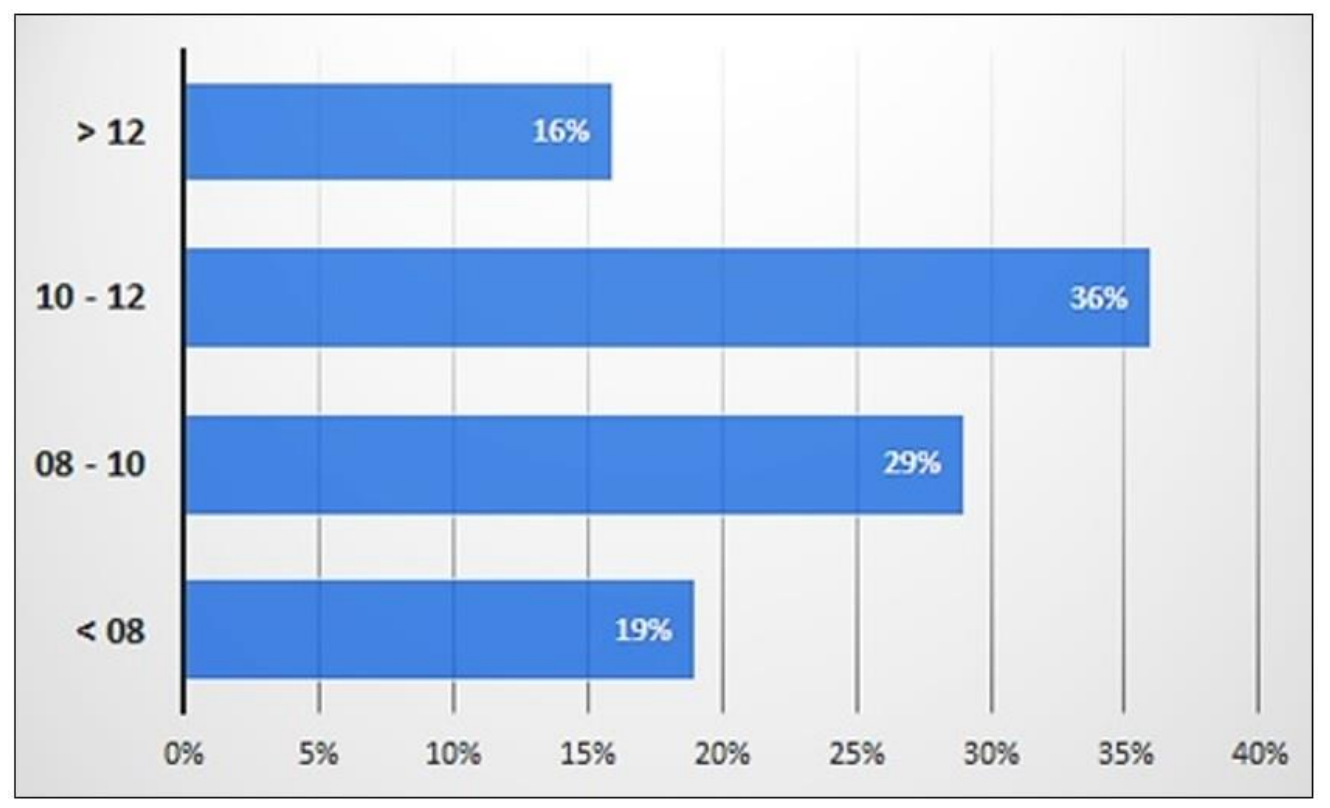

Fig. 5. Distribution of students according to their AAM obtained score average.

To get an idea of the AAM distribution by gender, a ratio was calculated between boys and girls according to the AAM intervals obtained (sex ratio AAM). It seems clear that the value of sex ratio is inversely correlated with the value of the AAM with a regression coefficient $\mathrm{R}^{2}=0.95$ (Fig. 6). It turns out that girls have better marks, with an AAM of over 10/20 compared to boys. This observation can be explained by the fact that girls, in those rural areas, find their schooling as a way to escape the rough tasks at home (guarding little brothers, linen, chore of water ...), in the other hand, the situation of girls is critical, because they may pulled out from school for a simple mistake, it is up to them to balance between their domestic obligations, and sometimes outside in the fields, considered as priority, and to obtain good results, therefore, the majority of girls get good marks compared to the boy. This finding can also be observed at the national level in primary, intermediate and secondary schools, girls have a lower repetition rate and a high dropout rate than boys (CSEFRS 2019). 


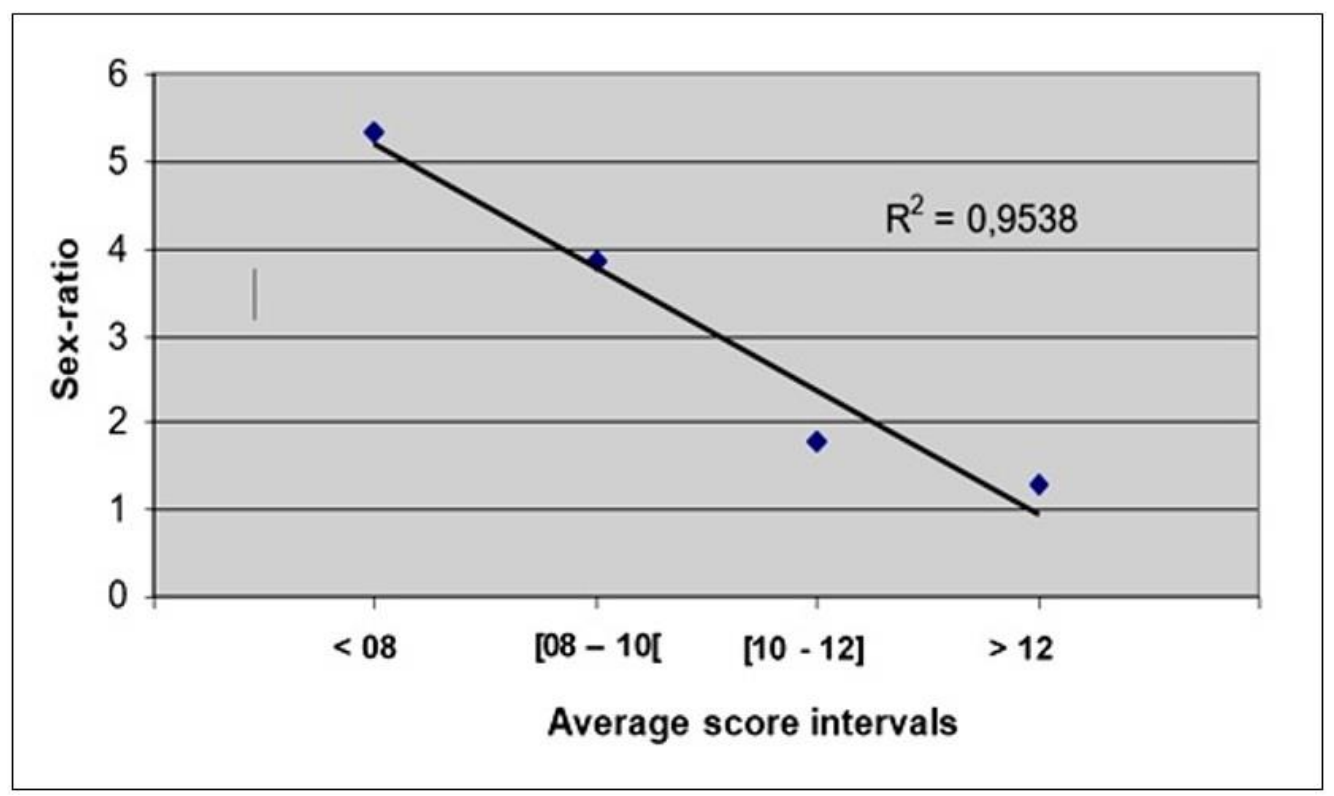

Fig. 6. Distribution of student's average score according to the sex-ratio.

The effect of father's occupation factor (FOF) on the dependent variable AAM of students, differentiates three categories and clearly shows the separation of the group "farmers of cannabis" from the other groups ("Farmers of other cultures" and "Other occupations") (Fig. 7). In fact, the student who come from families that grow cannabis (group 1) shows a fairly low schooling performance compared to other students. This fact was reflected by an AAM less than 9.5 out of 20. Moreover, the survey conducted in this region showed that children aged between 12 to 16 are actively involved in cannabis cultivation, especially in the field monitoring ${ }^{5}$, harvesting period, transport, and threshing for obtaining resin. Therefore, it seems that the cultivation of cannabis has direct effects on schooling performance of children, and boys are more affected.

\footnotetext{
5 Through "control towers" or "Nouwala" made manually from the stems of trees and canes, cannabis farmers monitor fields in turn, day and night. Schoolchildren are thus participating in this process, and thus disrupting their educational pathways
} 
The Journal of Quality in Education (JoQiE) Vol.11, N¹8, November 2021

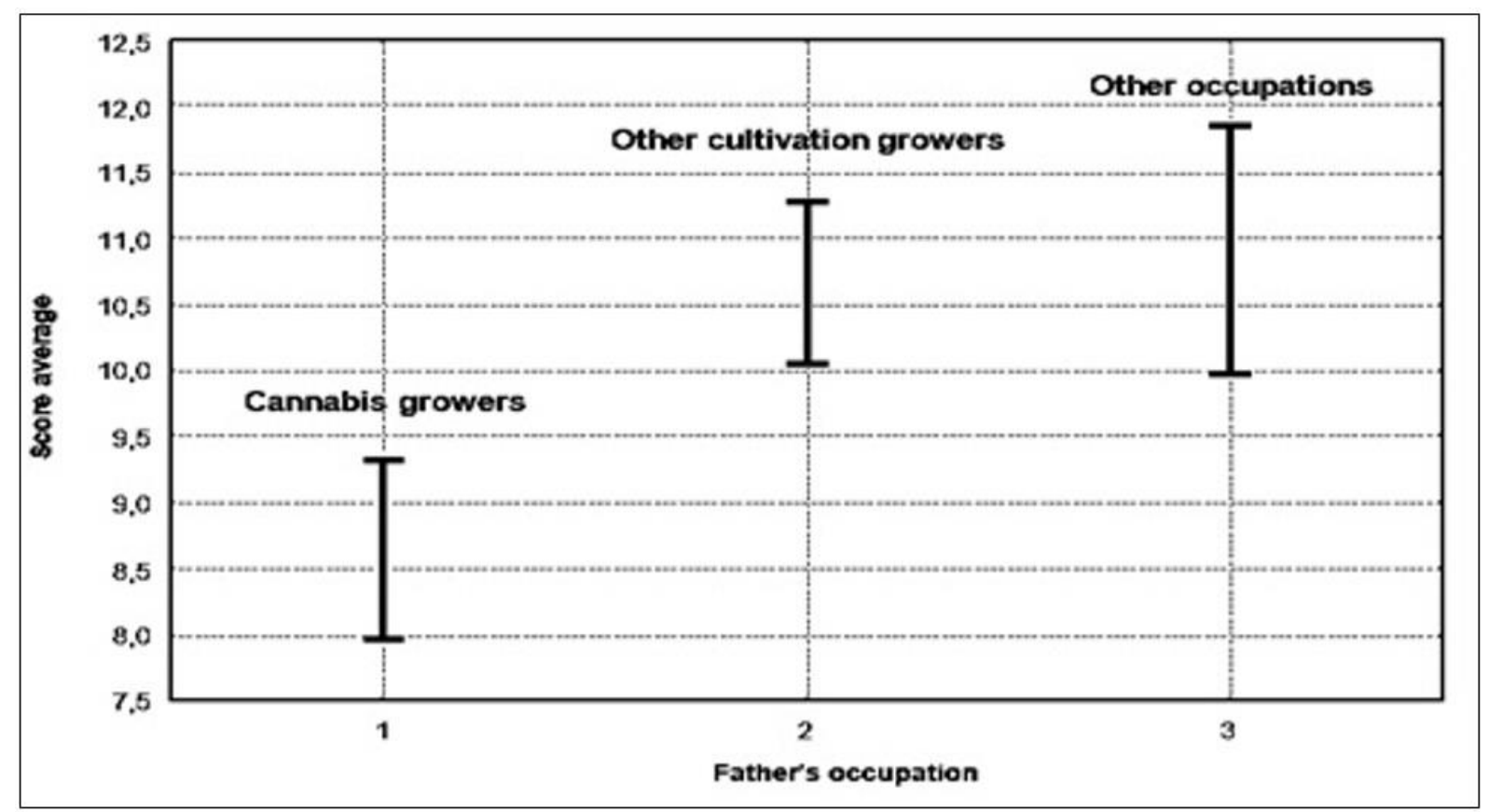

Fig. 7. Impact of father's occupation on average score of his children. Common Effect: F (2, $97)=12.154, p<=0,001002$, Effective Hypothesis Decomposition, Vertical Bars represent Confidence Interval at $0.95 \%$

\subsection{Qualitative results:}

Personal attitudes towards education:

The preliminary approximation of the personal attitudes towards education of surveyed population highlights double and contrasting perspectives (Fig. 8). Firstly, although growing cannabis is more profitable than other crops, farmers perceive that the future of this culture is not guaranteed, does not offer a decent life and it is unstable and not secure way to make life, so they are aware of the importance of education for the lives of their children, as they said: " In general, parents want their children to study ". Secondly, the young people, do not yet understand the dangers involved in a particular sector of agricultural activity, they are proud of their profits, for them it is a quick way of profit. In addition to that, due to the proximity of the Mediterranean coast, they think obsessively about immigrating on a boat. This idea of leaving the country is widespread even in the youngest children. 


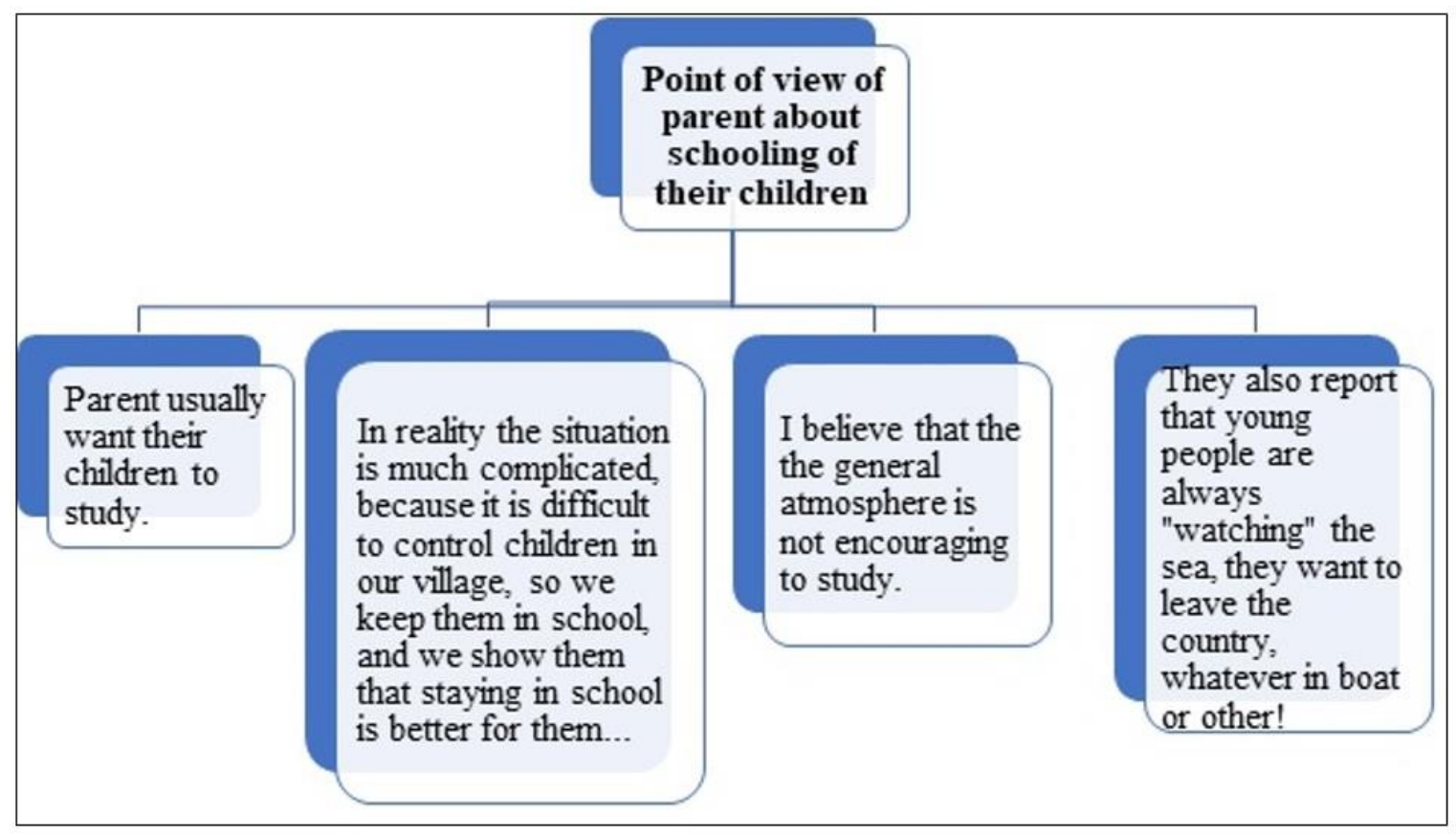

Fig. 8. Attitudes and behaviour of parents towards the schooling of their children.

For the educational infrastructure and necessary means:

The results (Fig. 9) show the opinions of the surveyed people (both parents, other adults and young people at the school age) about the schooling problems in the study area. The respondents distinguished three fundamental aspects: Lack of educational infrastructures, lack of human resources (teachers) and, lack of authorities' involvement. According to one of the respondents: "the authorities do not have, in these moments, a clear strategy to provide a sustainable solution". He also mentioned an important missing element, the girls' boarding school with capacity that satisfies the needs of schooling girls from distant villages. In fact, the similar institutions exist, but with a limited number of beds, which implies that a limited number who will benefit. Boys can find an alternative, to congregate among themselves and rent houses. While for girls, the absence of beds is one of the reasons that can deprive them of their integration into school life.

According to the surveyed people, responding about the physical conditions of the local school building they insist on the need to improve and develop the pre-existing educational 
infrastructure in the area, to develop classes that are sometimes in ruins and rehabilitate schools. In addition to that, the lack of equipment for proper functioning of secondary education institutions is accentuated by the deterioration of what is already present, (didactic materials, etc.). One of the interviewed fathers expressed his dissatisfaction within this issue, he describes: "My son told me that many tables on which they are writing is broken, the instructor contacted a lot of times his school director about this subject without any response, and finally, he fixed it, but in the very bad manner!.."

As a result, the participants in this survey agree that their daily lives of the local population seem to be on the fringes of the contexts and intentions of interest of local authorities and without institutional involvement.

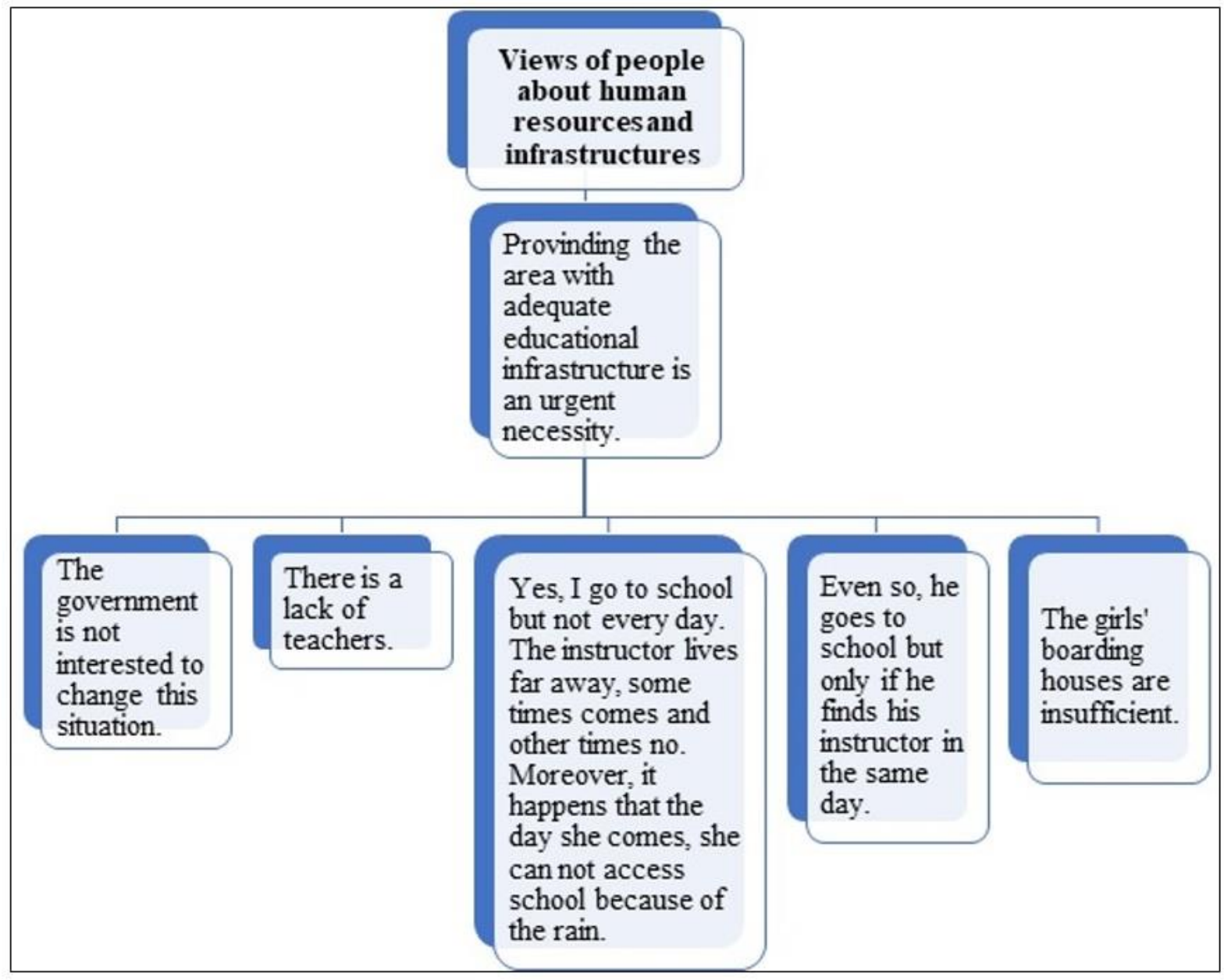

Fig. 9. For the educational infrastructure and necessary means in the study area. 


\section{Continuity of schooling:}

According to the respondents (Fig. 10), the continuity of education among young students is considered essential. They affirm that education certainly offers opportunities of the future, since being a graduate allows, although in a difficult way, to find an place in the labour market, as a respondent described: "Yes, indeed, my children will have to make their obligation to finish their schooling, the next turn is from the authorities, which has the obligation to find the work for them". On the other hand, the desire and obligation to continue schooling is sometimes blocked, during rainy days, by severe climatic conditions (continuous rainy days...) and combined, in some cases, with the disastrous state of the roads to school, which prevent access by students and teachers to join the school, this occurs especially in the mountainous areas of the study area. However, the problem lies in the difficulty to go beyond primary education. This is due to "the need for manpower to take care of family farms" especially for children over 13 years old. On the other hand, the family in rural area requires labour to carry out farming activities including cannabis cultivation, which is a dominant trend within this area of study, and other tasks such as cattle breeding, mowing the grass and harvesting. In this case, young children play decent role of taking care specially of cannabis plantations and its growth.

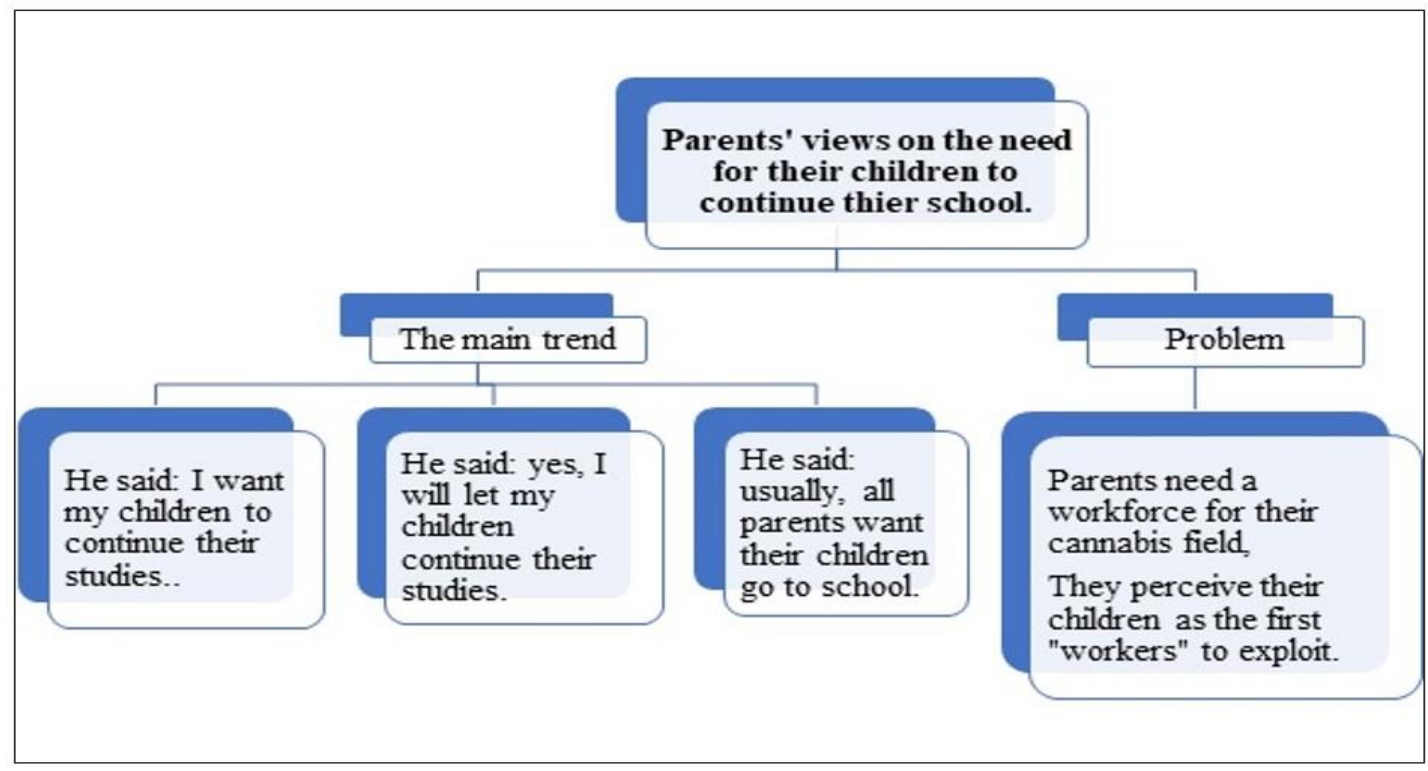

Fig. 10. Parents' opinions on the continuity of schooling of their children. 


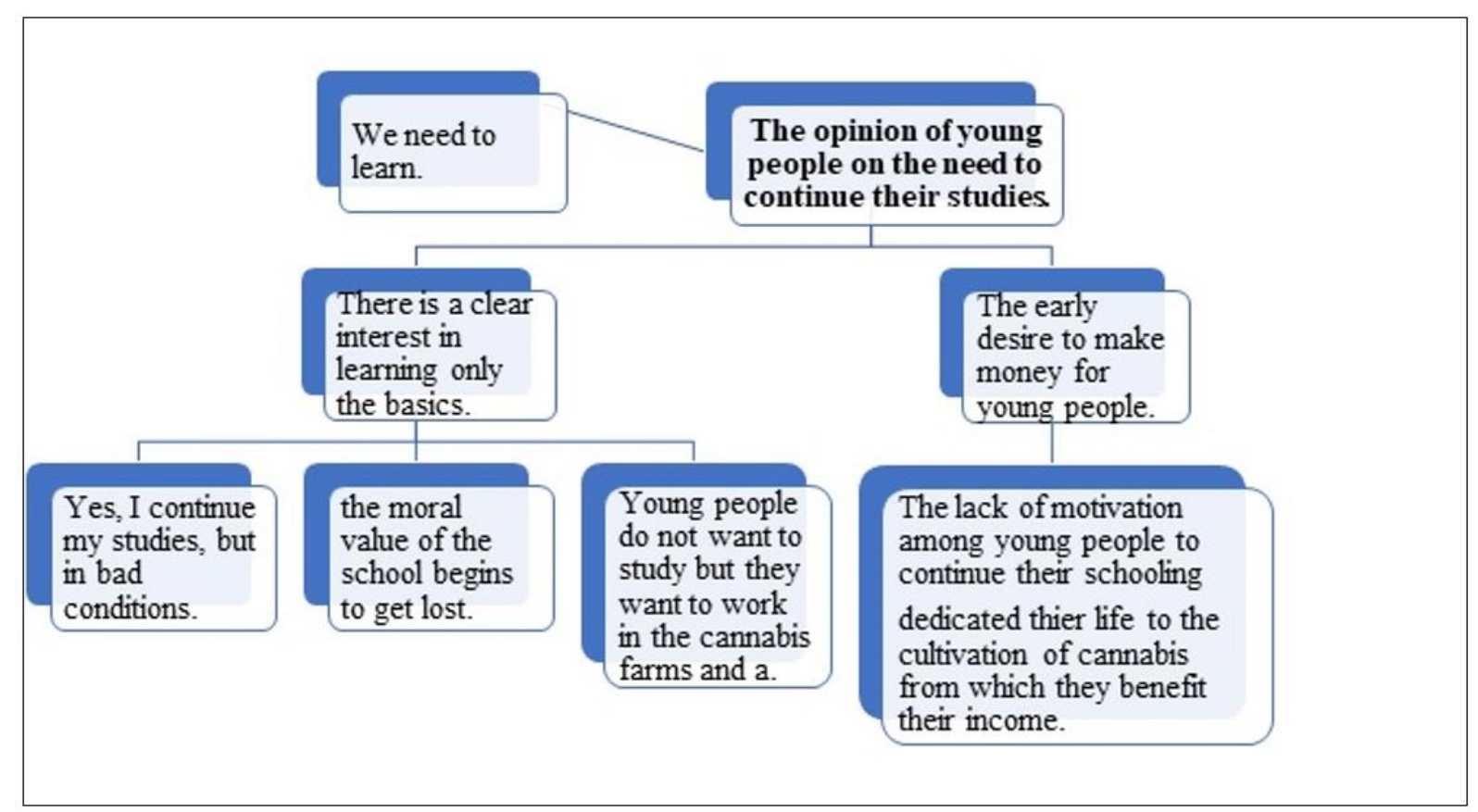

Fig.11. Young people's views on the continuity of their schooling.

Apart from those who have expressed their intention to continue their schooling, the rest of the surveyed young people showed their interest to learn only basic notion (reading and writing). In our study area, there is a general dominance trend that marginalizing schooling due to the uncertain outcome after graduation. This negative cultural perception towards schooling, unfortunately encourage students to lose faith in school and leave school as early as they can to earn money by working in cannabis field.

So, the idea of " earning money " and disposing of income is the most dominant trend among the young students of the study area. This through their early implication in the activities related to cannabis cultivation, a student firmly shared that: "We prefer to work in the family plots of cannabis than going to school!". The cultivation of cannabis then allows the young people of the studied zone to achieve economic independence at an early age, with serious changes for their career and personality. Without forgetting that they play the role of head of the family if the father is absent either in prison or wanted by the justice ${ }^{6}$.

${ }^{6}$ This is a real social phenomenon in the North of Morocco, the wanted people are those peasants who have cultivated illegally cannabis and who have been summoned by the authorities to answer for this crime. The peasant prefers not to go there, for fear of ending up in prison, and therefore lives in hiding and fear of being arrested. 


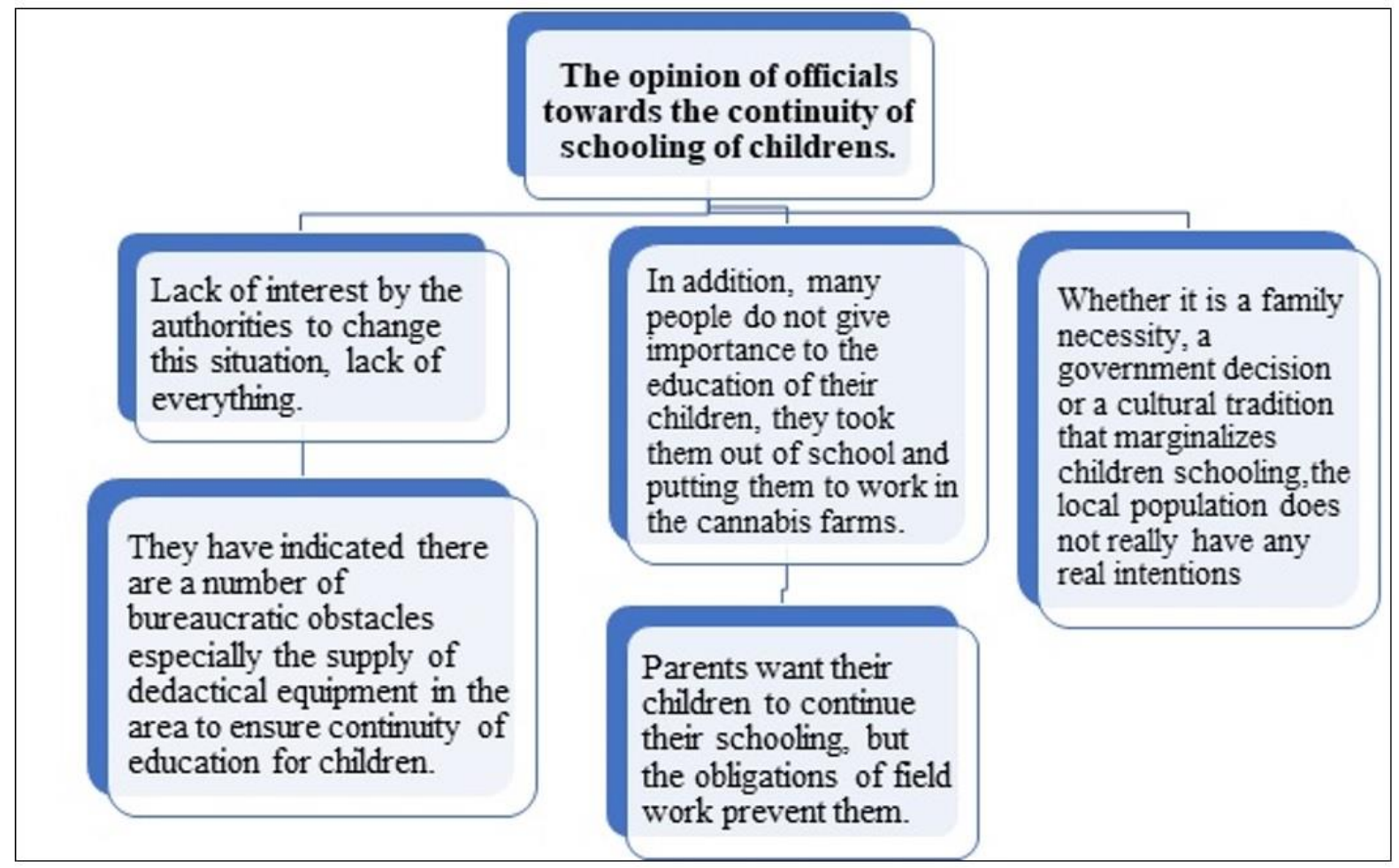

Fig.12. Opinions of the officials and others working in the education sector towards the schooling of children.

The figure 12 shows the opinions of the officials and others personnel involved or interested in children schooling in the concerned municipality, such as teachers, people with a respected social status in the village (Sheikh, Fquih, etc.), elected officials, representatives of institutions. According to many farmers, that express almost the same opinions: "We still face the challenges of field work obligations, growing cannabis adds other burdens", because the growing season of cannabis cultivation almost match school year (UNODC 2003), which seriously hinders the schooling of children who participate in cannabis cultivation. This problem is clearly manifested during the preparation period for passing the exams at the end of the year, because it coincides with that of the growth of growth of cannabis which implies the need to take care of it, in particular the time of watering the plants which often take place at night, the optimal moment to rest, which causes fatigue and lack of focus for these students during the day. Moreover, the fact that the farmers assert the necessity of earning income is more important than schooling, so they undisclosely exploit their children as less expensive work forces to minimize the costs of growing and protecting cannabis crop. Other respondents 
The Journal of Quality in Education (JoQiE) Vol.11, N¹8, November 2021

who work in the education sector stated that most of the local population is very negligent or indifferent towards the education of their children and clearly perceive insufficient efforts made by the authorities towards this issue.

\section{Discussion:}

The current study attempts to fill the gap in the literature regarding the effect of cannabis cultivation on scholastic performances, through measuring students' achievement in area where cannabis cultivation is widespread. The study area covers the municipality of "Stehat", coastal part of eastern Chefchaouen province, northern Morocco.

The quantitative analysis demonstrated the remarkable interplay between the students' achievement and parents'work. In fact, the professional background activities linked to the cultivation of cannabis revealed to have a negative impact on students' schooling in the studied area. Along the same lines, according to the latest Moroccan CSEFRS report in 2019, gender analysis reveals that girls outperform boys in their MAA, in a way that directly affects the dropout rate, mainly among boys, in secondary schools in these rural areas. (CSEFRS 2019), while in primary schools' dropout by sex affects $5.6 \%$ of girls against $4 \%$ of boys. We can therefore see that the boys most concerned by dropping out of school in middle and secondary schools in rural areas. Similar results were observed concerning the cultivation of "Khat", a plant with psychotropic effect, in Kenya (Ngeranwa 2013) where the Khat cultivation influenced the enrolment of children in primary schools and the impact was more severe on boys than girls. Students from families that practice Khat farming performed lower in school than those from nonKhat farming families.

The qualitative complement of the data analysis of this study showed that the population, even if it claims the need for learning for their children, it is not aware, understandable and yet imbued with the value and importance of education, however they feel a negative attitude 
towards school, which does not allow them to find a job for their children. As a result, this frustration further reduces the already low level of trust toward education institutions ${ }^{7}$. Other related factors that indirectly affect the scholastic performance and the continuity of schooling of the local students, are the deterioration of educational infrastructure, the lack of equipment and insufficient/qualified human resources for education. Together, these factors encourage students to drop out of school, and redirected toward the attractive cannabis cultivation at an early age, which sometimes puts them at risk for their own safety ${ }^{8}$.

Moreover, despite the extension of the cultivation of cannabis in the region and the acquisition of the technical equipment, and import external workforces to work in the fields of cannabis, the population retains always the same practice and maintains the habit of exploiting the workforce within the family for supervising and monitoring. Involving their own children in cannabis cultivation is above all due to illicit aspect of this practice that requires above all the trust between practitioners, also, sieving ${ }^{9}$ is the most delicate step in this illegal activity and requires the intervention of a support person, most often the most vulnerable members of the family: children.

Furthermore, including the opinions of professionals of the education sector was of major importance. It highlights the bipolarity of views regarding the education of children in the studied area and demonstrates the presence of a deep gap in education coordination between the local population, elected officials and stakeholders.

It should not be forgotten that the survey was carried out in an atmosphere where distrust reigns among cannabis farmers towards any "foreign person". So, establishing individual relationships with cannabis growers and building trust was very difficult. Additionally, the

\footnotetext{
7 Trust in Institutions Index: Preliminary Findings by the Moroccan Institute For Politic Analysis (2019). https://mipa.institute/7141

8 https://www.hcp.ma/Le-travail-dangereux-des-enfants-ages-de-7-a-17-ans-au-Maroc a1755.html

9 A large plastic bowl on which it is install piece of nylon fabric that will serve as a sieve thereafter, the mesh allowing the top inflorescences of cannabis to pass whigh will accumulate in resin form.
} 
study should be much more spread over other regions in the north of Morocco marked by the cultivation of cannabis. Moreover, the limits of this study include its extension to a limited locality characterized by the cultivation of cannabis on their mountain, therefore, cannot be generalized outside the same region.

Finally, the studied phenomenon is represented by a small sample size due to the fact that conducting surveys in schools requires specific authorization and many coordination between local and provincial educational institutions, and the student's families, that is difficult to carry out. Despite these limitations, this study provides some interesting insights into the schooling performance of students coming from families that grow cannabis.

\section{Conclusion:}

In this article, the scholastic performance in an area where cannabis cultivation prevails, was analysed through combining the quantitative and the qualitative method. The results show a significant effect of cannabis cultivation on students' performance and highlight a general trend to integrate children from an early age into cannabis farming activities. This trend generates disruptions in their schooling and produces a lack of interest in education in general in the region, especially with inadequate and discouraging infrastructure.

The results also suggest that, despite many reform plans that experienced the Moroccan education system, several indicators remain negative so that the country gets unsatisfying ranking in the Human Development Index. This part of the rural territory in the north of the kingdom can therefore give a clear image of the output of this sector in Morocco. If the government does not step forward in seeking real solutions to these problems, it will continue to lose its development goals and deprive students of their right to a fair and quality education; as well as their right to obtain a certification or a diploma supposed to help them flourish, build their future and participate in the full development of their country. Furthermore, all reform 
The Journal of Quality in Education (JoQiE) Vol.11, N¹8, November 2021

plans have reached their validity without any progress. Authorities and decision-makers must react and propose alternative solutions for the study region and for the whole country. They will have to prioritize an increase in budget dedicated to the education sector, provide adequate infrastructure (roads, tracks, electrification ...), prepare highly qualified and motivated human resources, because investing in human capital directly generates economic development.

\section{Acknowledgements:}

The authors thank all informants from Stehat village for their contribution and special thanks to the editors and the anonymous reviewers whose feedback and comments are of great help to the improvement of the manuscript.

\section{ORCID:}

Yassin Meklach, ID https://orcid.org/0000-0003-3012-2183

\section{Funding:}

This research received no specific grant from any funding agency in the public, commercial, or not-for-profit sectors.

\section{References:}

Anglin, D. M., Corcoran, C. M., Brown, A. S., Chen, H., Lighty, Q., Brook, J. S., Cohen, P. R. "Early cannabis use and Schizotypal Personality Disorder Symptoms from adolescence to middle adulthood” Schizophrenia Research, 137(1-3), 45-49, 2012.

doi:10.1016/j.schres.2012.01.019 
The Journal of Quality in Education (JoQiE) Vol.11, N¹8, November 2021

Beck, K. H., Caldeira, K. M., Vincent, K. B., O’Grady, K. E., Wish, E. D., Arria, A. M. “The social context of cannabis use: Relationship to cannabis use disorders and depressive symptoms among college students” Addictive Behaviors, 34(9), 764-768, 2009. doi:10.1016/j.addbeh.2009.05.001

Bidwell, L. C., Henry, E. A., Willcutt, E. G., Kinnear, M. K., Ito, T. A. "Childhood and current ADHD symptom dimensions are associated with more severe cannabis outcomes in college students” Drug and Alcohol Dependence, 135, 88-94, 2014. doi:10.1016/j.drugalcdep.2013.11.013

Creswell, J. W., \& Plano Clark, V. L. "Designing and conducting mixed methods research" Thousand Oaks, CA: SAGE Publications Inc, pp 488, 2011.

Chabrol, H., Chauchard, E., Goutaudier, N., \& van Leeuwen, N. "Exploratory study of the psychopathological profiles of adolescent cannabis users” Addictive Behaviors, 37(10), 1109_ 1113, 2012. doi:10.1016/j.addbeh.2012.05.005

Coffey, A., \& Atkinson, P. "Making sense of qualitative data: Complementary research strategies”, Sage Publications, pp 216, 1996.

Jones, C. B., Meier, M. H., Pardini, D. A. "Comparison of the locations where young adults smoke, vape, and eat/drink cannabis: Implications for harm reduction" Addictive Behaviors Reports, 8, 140-146, 2018. doi:10.1016/j.abrep.2018.09.002

CSEFRS (Conseil Supérieur de l'Éducation, de la Formation et de la Recherche Scientifique). Atlas Territorial de l'abandon scolaire, Analyse des parcours de la cohorte 2014-2018 et cartographie communale, Rabat, 2019. 
The Journal of Quality in Education (JoQiE) Vol.11, N¹8, November 2021

Dammert, A. C. "Child labor and schooling response to changes in coca production in rural Peru” Journal of Development Economics, 86(1), 164-180, 2008.

doi:10.1016/j.jdeveco.2007.06.007

Deschenaux F., “Analyse du champ de la recherche en sciences de l'éducation au regard des méthodes employées : la bataille est-elle vraiment gagnée pour le qualitatif ?” Recherches qualitatives, 27, pp 5-27, 2007.

Fylan F. "Semi-structured interviewing”, in: Miles, J. \& Gilbert, P. (Eds.) A Handbook of Research Methods for Clinical and Health Psychology, 5, pp. 65-78, 2005.

GCR (Global Competitiveness Report) by World Economic Forum, 2017 - 2018.

HCP (Haut-commissariat au plan), Les indicateurs sociaux du Maroc, 2018.

Holstein, J.A., Gubrium, J.F. “Active Interviewing”, In: Silverman, D. (Eds.), Qualitative Research: Theory, Method and Practice, Sage, London, pp. 113-129, 1997.

Manzar A., Avants B., Cyckowski L., Cervellione K. L., Roofeh D., Cook P., Gee J., Sevy S, Kumra S. "Medial temporal structures and memory functions in adolescents with heavy cannabis use", Journal of Psychiatric Research , 45(8), 1055-1066, 2011. doi:10.1016/j.jpsychires.2011.01.004

Mason, M. J., Brown A., Moore, M., “The accuracy of young adult cannabis users' perceptions of friends' cannabis and alcohol use", Addictive Behaviors 95, 28 - 34, 2019. doi: 10.1016/j.addbeh.2019.02.021

Meklach Y., Haluza, R. D, Kadiri M., El Ouahrani A., Molero Mesa J., \& Merzouki A. "Cannabis cultivation within a religious context: A case study of Ghomara in the Rif Mountain (Northern Morocco)", Journal of Ethnicity in Substance Abuse, 18(1), 45 - 66, 2017. Doi :10.1080/15332640.2017.1300972. 
The Journal of Quality in Education (JoQiE) Vol.11, N¹8, November 2021

Meklach, Y., Sanchez Alhama, J., Molero Mesa, J., Martos, A. V., Ouahrani, A., Merzouki,

A. "Cannabis and sustainable development in Ghomara's mountains (western coastal part of Rif-North of Morocco): The gender makes the difference?" Journal of Sustainable Development in Africa, 12(3), 2010.

Morales, E., Ariza, C., Nebot, M., Pérez, A., Sánchez, F. “ Consumo de cannabis en los estudiantes de secundaria de Barcelona: inicio en el consumo, efectos experimentados y expectativas”. Gaceta Sanitaria, 22(4), 321-329, 2008.

Ngeranwa Daniel J. N. "Impact of Khat cultivation on educational performance among upper primary schools' pupils in Gachoka division”, Embu County, Kenya, MSc. Thesis, The school of environmental studies of Kenyatta University, 2013.

OECD (Organisation for Economic Co-operation and Development). PISA 2018 Results (Volume I): What Students Know and Can Do, PISA, OECD Publishing, Paris, 2019. https://doi.org/10.1787/5f07c754-en.

Pacoricona Alfaro, D.L., Ehlinger, V., Spilka, S., Ross, J., Sentenac, M., Godeau, E. "Alcohol, tobacco and cannabis use: Do students with mild-intellectual disability mimic students in the general population?" Research in Developmental Disabilities, 63, 118-131, 2017. doi:10.1016/j.ridd.2016.10.009

Pérez, A., Ariza, C., Sánchez-Martínez, F., Nebot, M. “Cannabis consumption initiation among adolescents: A longitudinal study”, Addictive Behaviors, 35(2), 129-134, 2010. doi:10.1016/j.addbeh.2009.09.018

Rasic, D., Weerasinghe, S., Asbridge, M., Langille, D.B. “Longitudinal associations of cannabis and illicit drug use with depression, suicidal ideation and suicidal attempts among Nova Scotia high school students. Drug and Alcohol Dependence, 129(1-2), 49-53, 2013. doi:10.1016/j.drugalcdep.2012.09.009 
The Journal of Quality in Education (JoQiE) Vol.11, N¹8, November 2021

RGPH (Recensement générale de la population et d'habitat) "Population légale d'après les résultats du RGPH 2014” sur le Bulletin officiel N 6354 .

Schultz, N.R., Bassett, D.T., Messina, B.G., Correia, C.J. "Evaluation of the psychometric properties of the cannabis use disorders identification test - revised among college students", Addictive Behaviors, 2019. doi:10.1016/j.addbeh.2019.02.016

Shapiro, G. K., \& Buckley-Hunter, L. "What every adolescent needs to know: Cannabis can cause psychosis”, Journal of Psychosomatic Research, 69(6), 533-539, 2010.

doi:10.1016/j.jpsychores.2010.04.002

Silverman, D. “Doing qualitative research. A practical handbook”, London, UK: Sage, pp 336, 1999.

Small ML. "How to conduct a mixed methods study: Recent trends in a rapidly growing literature” Annu. Rev. sociology. 37, pp 57 - 86, 2011.

UDHR (United Nations, Universal Declaration of Human Rights). General Assembly resolution 217 A. 1948.

UNODC (United Nations Office on Drugs and Crime), Maroc. Enquête sur le cannabis 2003, Vienne, UNODC, 2003.

Walukevich-Dienst, K., Neighbors, C., Buckner, J. D. “Online personalized feedback intervention for cannabis-using college students reduces cannabis-related problems among women”, Addictive Behaviors, 98, 106040, 2019. doi:10.1016/j.addbeh.2019.106040

World Bank. "Ending learning poverty: What will it take?" Conference version. Washington, DC: World Bank. 2019. 